\title{
EVACUATION OF THE VERY YOUNG
}

\section{$\mathrm{T}$} HE further report on evacuation (Evacuation : the Under Fives. August 1940) by the Evacuation Committee of the Association of Architects, Surveyors and Technical Assistants deserves wider attention than it appears to have yet received, particularly in view of the determined policy of evacuation urged by Lord Horder and the statement of Mr. Malcolm MacDonald, Minister of Health, to the House of Commons on October 17. Mothers and children, he said, are leaving London at the rate of several thousands a day. Already about 489,000 school children or some 56 per cent of the school children in the London evacuation areas had left, and 300,000 out of 500,000 in the L.C.C. area had gone to reception areas.

This movement, which gains part of its present importance by the indirect consequence of reducing the demand for deep shelter and the risk of overcrowding, removes to safer areas some of those most liable to dangers to health which attend nights in deep shelters, apart from the special risks of overcrowding. From every point of view their removal out of London is to the good, but as was shown in the report to the Fabian Society edited by Richard Padley and Margaret Cole entitled "Evacuation Survey" (see NatuRE, October 5, p. 439) the evacuation of very young children presents special difficulties and problems. The present report makes a very definite contribution to an acute problem, and adoption of its recommendations should prevent a number of the mistakes made in the earlier evacuation being repeated as well as offer safeguards for the health of those going to the reception areas.

The report points out that in August some 750,000 babies, belonging to about 500,000 mothers, were in dangerous areas, as well as more than a million children between two and five. Any evacuation scheme to the relatively safe areas must be based on a thorough re-zoning of the British Isles by competent military and civil authorities taking into account both types of dangerous area. The failure of the first scheme is attributed to lack of consideration for the psychology of family life, coupled with a lax definition of safety areas, the absence of satisfactory arrangements to accommodate mothers with young children, and the placing of the responsibility for carrying out the scheme on local authorities who were not sufficiently interested or qualified. The principle of evacuation was not at fault. Failure of the general scheme as a whole was due to insufficient understanding of the problems which are involved and refusal to deal with the many deficiencies that appeared by financing a workable scheme.

The scheme put forward in this report is founded on the belief that no baby under two years old should be sent away from its mother unless in special circumstances a close and suitable friend can be found to act continuously as a foster-mother. Most two- to five-year olds can be successfully separated from their parents if a mother substitute looks after them in small groups. Groups of four or five children may be joined together in school units of not more than twenty children.
An evacuation allowance should be available for mothers of babies under two or of several children under five, so that they have a free choice of whether to evacuate or not. Evacuated mothers must have independence in managing their own families and must be fully used in caring for other unaccompanied children. Visits by husbands must be possible, and for this purpose reduced fares and overnight accommodation must be provided. Temporary day nurseries must be set up for all children under five in the dangerous areas as part of the organization for evacuation and to establish confidence in it. Welfare centres and young people's hostels will also be required for members of the family who are left behind. Local authorities in the dangerous areas should be empowered to act equally with those of the reception areas in initiating evacuation arrangements.

The second essential is proper accommodation in the reception areas. The only way of evacuating mothers and young children immediately is into group billets, and accordingly it is proposed that the large country houses in safe areas should be immediately requisitioned for the reception of three quarters of a million mothers and children under five. A building programme is also essential. This should be carried out in stages; first, making all suitable existing buildings usable ; second, providing sleeping and feeding accommodation; and third, the provision of day crèches, playrooms and staff accommodation. The report suggests that less alteration than is often supposed will be required for the large houses. The extra sleeping and feeding accommodation to be constructed includes family cottages and hostels for mothers and babies, and sleeping and feeding sections of residential nursery schools for children of two to five years.

This building programme avoids, to a great extent, using materials which are imported or urgently wanted for war purposes, and skilled site labour. An adequate quota of materials and labour must, however, be made available by the Government. The whole cost of the scheme is estimated at $£ 100-£ 140$ millions, and this expenditure would have important results in morale and organization during the War as well as provide permanent assets to the community.

The second part of the report gives details of the recommended planning standards for the new buildings proposed with detailed suggestions for economy of available materials in construction and sketches of typical designs for the alteration of existing country houses and the erection of family cottages for two mothers and children, a hostel for twelve mothers and children, a day crèche for twenty children under two years old and a residential nursery school for forty children in two separate groups with a matron, two assistant teachers, eight foster mothers and a cook.

The report appears to represent exactly that type of positive criticism for which Mr. Bevin recently appealed and indicates the opportunity which still remains for retrieving past mistakes and profiting by them to build better. 